\title{
openheart Cardiac rehabilitation using the Family- Centered Empowerment Model versus home-based cardiac rehabilitation in patients with myocardial infarction: a randomised controlled trial
}

Amir Vahedian-Azimi, ${ }^{1}$ Andrew C Miller, ${ }^{2,3}$ Mohammadreza Hajiesmaieli, ${ }^{4}$ Mari Kangasniemi, ${ }^{5}$ Fatemah Alhani, ${ }^{6}$ Hosseinali Jelvehmoghaddam, ${ }^{7}$ Mohammad Fathi, ${ }^{4}$ Behrooz Farzanegan, ${ }^{8}$ Seyed H Ardehali, ${ }^{9}$ Sevak Hatamian, ${ }^{10}$ Mehdi Gahremani, ${ }^{4}$ Seyed M M Mosavinasab, ${ }^{1}$ Zohreh Rostami, ${ }^{11}$ Seyed J Madani, ${ }^{12}$ Morteza Izadi $^{13}$

To cite: Vahedian-Azimi $A$ Miller AC, Hajiesmaieli M, et al. Cardiac rehabilitation using the Family-Centered Empowerment Model versus home-based cardiac rehabilitation in patients with myocardial infarction: a randomised controlled trial. Open Heart 2016;3:e000349. doi:10.1136/openhrt-2015000349

Received 6 October 2015 Revised 14 March 2016 Accepted 15 March 2016

CrossMark

For numbered affiliations see end of article.

Correspondence to Dr Fatemah Alhani; Alhani_@@modares.ac.ir

\section{ABSTRACT}

Objective: To determine if a hybrid cardiac rehabilitation (CR) programme using the FamilyCentered Empowerment Model (FCEM) as compared with standard CR will improve patient quality of life, perceived stress and state anxiety of patients with myocardial infarction (MI).

Methods: We conducted a randomised controlled trial in which patients received either standard home CR or CR using the FCEM strategy. Patient empowerment was measured with FCEM questionnaires preintervention and postintervention for a total of 9 assessments. Quality of life, perceived stress, and state and trait anxiety were assessed using the 36-Item Short Form Health Survey (SF-36), the 14-item Perceived Stress, and the 20-item State and 20-item Trait Anxiety questionnaires, respectively.

Results: 70 patients were randomised. Baseline characteristics were similar. Ejection fraction was significantly higher in the intervention group at measurements $2(p=0.01)$ and $3(p=0.001)$. Exercise tolerance measured as walking distance was significantly improved in the intervention group throughout the study. The quality of life results in the FCEM group showed significant improvement both within the group over time $(p<0.0001)$ and when compared with control $(p<0.0001)$. Similarly, the perceived stress and state anxiety results showed significant improvement both within the FCEM group over time $(p<0.0001)$ and when compared with control $(p<0.0001)$. No significant difference was found either within or between groups for trait anxiety.

Conclusions: The family-centred empowerment model may be an effective hybrid cardiac rehabilitation method for improving the physical and mental health of patients post-MI; however, further study is needed to validate these findings. Clinical Trials.gov identifier NCT02402582.

Trial registration number: NCT02402582.

\section{KEY QUESTIONS}

What is already known about this subject?

- Cardiac rehabilitation (CR) is an outpatient model of chronic disease management for secondary cardiovascular disease (CVD) prevention. It is a class I indication for patients with coronary heart disease. The use of $C R$ postmyocardial infarction (post-MI) has been shown to improve function and exercise capacity, decrease morbidity and mortality, and also improves quality of life, perceived stress and anxiety. Hence, CR serves as a key tool in addressing the global burden of CVD. Despite recommendations, $\mathrm{CR}$ remains underutilised with low participation and adherence rates both in high income countries and low and middle income countries (LMICS). Home-based and hybrid CR programmes developed as a means to increase patient access, compliance and enrolment.

- The Family-Centered Empowerment Model (FCEM) was designed to improve the care and outcomes of patients with chronic diseases and has previously been evaluated and validated in a number of chronic disease states. Previously, it has been shown that the FCEM model may be feasible to use in the cardiac setting. Moreover, it has been reported to be effective among patients undergoing coronary artery bypass surgery. Its use in the non-surgical post-MI setting has not been defined.

\section{INTRODUCTION}

Cardiovascular disease (CVD) is a leading cause of death worldwide, accounting for $30 \%$ of global deaths. ${ }^{1}$ Over the next few decades, CVD will continue as the leading 


\section{KEY QUESTIONS}

What does this study add?

- CR remains underutilised and with high rates of patient attrition. This study utilises an approach to support structure engagement that has not previously been used in the post-MI population. Marked improvements in patient perceived physical and mental wellness as well as quality of life were observed. Improvements in ejection fraction and exercise tolerance were also observed. This strategy may effectively augment home CR to improve its effectiveness.

How might this impact on clinical practice?

- This study suggests that use of the FCEM to augment home CR may improve patients' physical health, mental health and quality of life versus attenuating the decline that may occur following discharge for acute MI. This may have the greatest clinical implications in resource-limited settings where CR access is low and attrition rates are high.

cause of mortality worldwide. ${ }^{2}{ }^{3}$ Furthermore, the burden of CVD is growing disproportionately in low and middle income countries (LMICs), where $80 \%$ of CVD deaths occur. ${ }^{4}$ Myocardial infarction (MI) is a leading cause of CVD-associated morbidity and mortality. ${ }^{5-7}$ Recurrent MI within 5 years is common, affecting $15-22 \%$ of patients' aged 45-64 years and 22\% of patients aged $>65$ years. ${ }^{6}$ In addition to the physical toll, an MI may cause or exacerbate significant mental health comorbid conditions.

The health-related quality of life (HRQoL) is increasingly being used as an outcome measure of coronary heart disease. ${ }^{8-10}$ As the population ages and survival of ischaemic coronary events continues to improve, assessment of HRQoL is necessary as an important and useful outcome measure complementing the traditional 'hard outcomes' such as mortality and recurrent MI for evaluating impact of disease and benefits of medical interventions. ${ }^{8}$ Post-MI increases in patient stress may translate into worse HRQoL. ${ }^{6}{ }^{11-13}$ Evidence suggests that a decline in health status is associated with worse prognosis, disease progression and healthcare outcomes in patients with cardiac disease. ${ }^{12}$ 14-16

Cardiac rehabilitation (CR) is an outpatient model of chronic disease management for secondary CVD prevention. It is a class I indication for patients with coronary heart disease. ${ }^{17}$ In a meta-analysis, the use of CR post-MI has been shown to improve function and exercise capacity, decrease morbidity and mortality, and also improves quality of life, perceived stress and anxiety. ${ }^{1}{ }^{18}$ Hence, CR serves as a key tool in addressing the global burden of CVD. ${ }^{1}$ Despite recommendations, CR remains underutilised with low participation and adherence rates in both high income and LMICs. ${ }^{1}$ The reasons for CR underuse include geographic access, cost, organisational and patient factors, and patient education and understanding of the nature of CR and the associated benefits. ${ }^{19-21}$ Participation in home-based or hybrid CR programmes is associated with costeffective and equivalent benefits to supervised programmes. ${ }^{22-24}$ With advances in technology, hybrid home-based programmes have been developed that incorporate email, secure websites and videoconferencing between patients and providers. Recently, the utility of smartphone applications has also been investigated. ${ }^{21}$

The Family-Centered Empowerment Model (FCEM) was designed and first reported by Dr Fatemah Ahlani at Tarbiat Modarres University. ${ }^{25}$ It's aim was to improve the care and outcomes of patients with chronic diseases and has previously been evaluated and validated in a number of chronic disease states. ${ }^{76-32}$ The primary aim of the model is to empower the patient/family unit to promote health quality. The model has four stages: (1) determining perceived threat (group discussion method); (2) self-efficacy (problem-solving method); (3) improving self-esteem (educational participation method) and (4) process and outcome evaluations. We investigated the impact that an FCEM-focused hybrid CR programme employing in-hospital and outpatient components, direct education, video teleconferencing and smartphone technology had on patient anxiety and perceived stress, and overall quality of life has measured by HRQoL among patients hospitalised with acute MI (AMI) in a coronary care unit (CCU).

\section{METHODS \\ Study design}

We conducted a randomised controlled blinded study in patients admitted for MI to the CCU of an academic teaching hospital from June 2012 to January 2015. The study was approved by the institutional investigative review board at Tarbiat Modares University and Baqiyatallah University of Medical Sciences and registered with Clinical Trials.gov (identifier NCT02402582). Inclusion criteria were: (1) age 45-85 years, (2) able and willing to provide informed consent, (3) willingness of designated family member or friend to participate, (4) is able to read, write, and fill out the questionnaire, (5) diagnosed with an AMI and (6) first hospitalisation for AMI. MI was diagnosed in accordance with established criteria including (1) clinical symptoms, (2) serum tests (eg, troponin and creatine kinase (CK)-MB) and (3) characteristic changes on the ECG. Cardiac catheterisation data were not routinely available. Patients had not previously gone through CR programmes. The difference between the two groups was not disclosed at any point. Patients consented knowing that they would receive cardiac rehabilitation, but without knowing the details. Patients and their designated family/friend were enrolled as a 'unit'.

Power calculations determined that 32 patient/family units were needed in each group to achieve a 95\% confidence level and a $90 \%$ power. Participant enrolment was via convenience sampling. Block randomisation was 
accomplished by a computer-generated random number list prepared by an expert statistician who had no clinical involvement in the trial. Allocation consignment was performed by the hospital clinical supervisor, who was not involved in the recruitment process. Patients and their family members, clinical nurses and data analyser were blind to the allocation. Analyses were performed as intention-to-treat.

\section{Intervention}

The intervention package had three phases including the preintervention, intervention and postintervention phases (figure 1).

\section{Preintervention}

During the preintervention phase, patients filled out questionnaires concerning quality of life, perceived stress and anxiety. A rehabilitation plan was formulated incorporating considerations for the patient's identified strengths' and weaknesses. See the CR section.

\section{Intervention}

Once discharged, patients called their study nurse every 2 days to report any problems or complications. Patients were evaluated by their primary cardiologist on a weekly basis and at 30 days. These examinations included history and physical examination, an ECG, and echocardiogram and laboratory tests as indicated. At other times, if patients experienced a problem or complication, they notified investigators and presented to either their primary cardiologist or their primary care provider for evaluation. Patients in the intervention group received care employing the FCEM in four stages. Stage 1 of the intervention was awareness and cognition. The patient was evaluated for their insight into their perceived illness severity and perceived sensitivity, or the degree to which they felt threatened by their illness. ${ }^{32}$ This was performed by means of 3-5 group sessions in the preintervention phase. Group sessions included $3-5$ patients and lasted for 45-60 min each. Session content included assessments of the participants' psychological and physical conditions as well as their attitude towards the nature, definition, risk factors, symptoms, medical and nursing care, and complications resulting from the MI.

In stage 2, patients were assessed for their expectations over 3-5 $1 \mathrm{~h}$ sessions. ${ }^{32}$ Groups of 3-4 patients shared and learnt from each other under the moderation and guidance of the principal researcher.

In stage 3, the degree of patient acceptance was assessed using an educational participation method in group discussion. Patients reached practical solutions through using the problem-solving findings of the previous stage.

Stage 4 consisted of formative and summative evaluations. ${ }^{32}$ The aim of the formative evaluation was to encourage patients to internalise their locus of control by seeing his/her self-empowerment (increasing selfresponsibility about their health). Summative evaluations were performed to evaluate the influence of the intervention on HRQoL dimensions, perceived stress and anxiety. The HRQoL dimensions, perceived stress and anxiety were assessed at baseline and at 3 months postintervention. Empowerment was measured at baseline and at 10 days postintervention by deploying FCEM questionnaires.

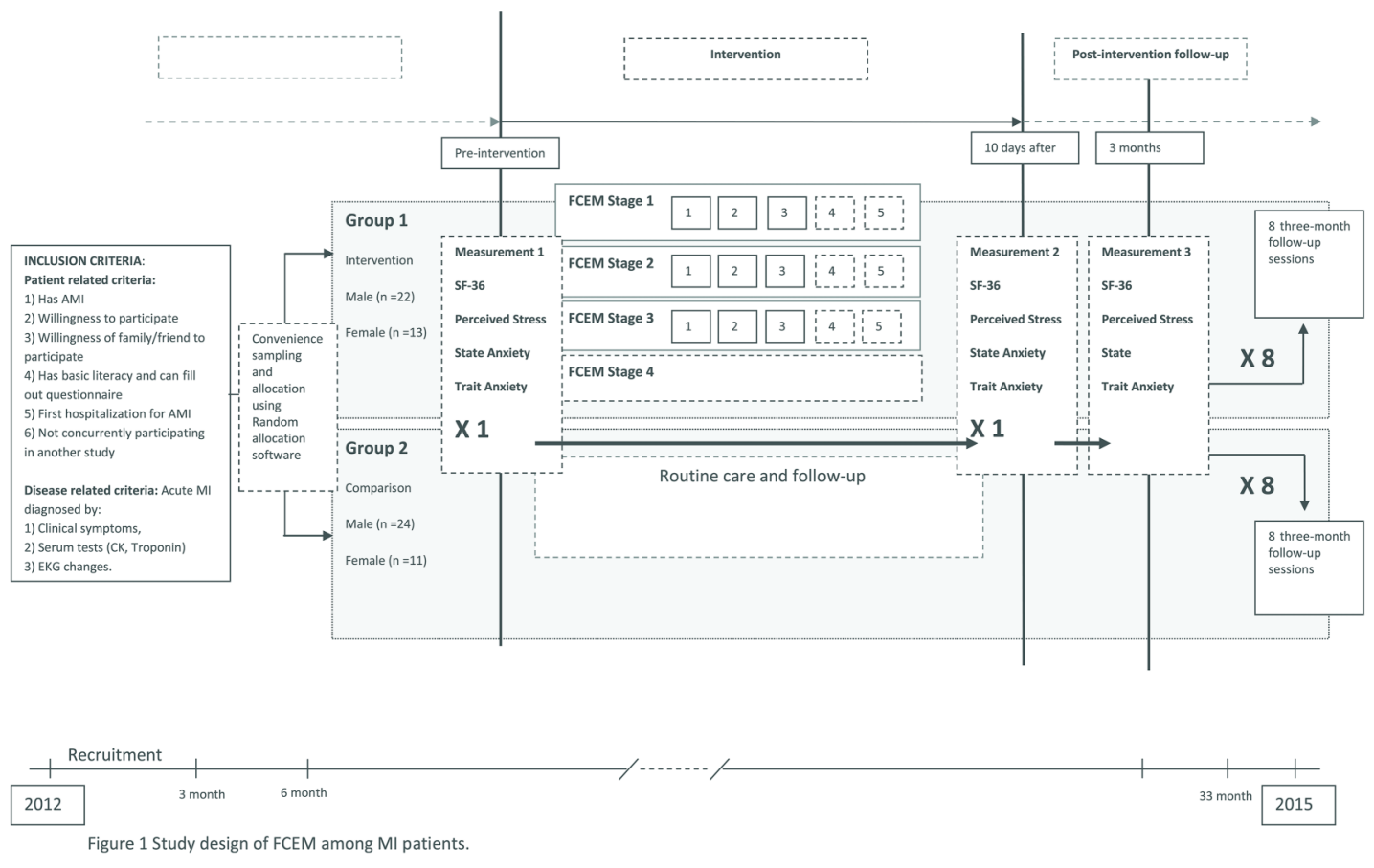

Figure 1 Study overview and design. AMI, acute myocardial infarction; CK, creatine kinase; FCEM, Family-Centered Empowerment Model; SF-36, 36-Item Short Form Health Survey. 


\section{Postintervention follow-up}

Phase 3 began 90 days following preintervention (control group), and 90 days postintervention (FCEM group). To assess the durability and stability of patient empowerment, patient knowledge, attitude and practice (KAP) was assessed over eight follow-up sessions at 3-month intervals. During the 24-month follow-up period, patients attended a total of 21 support-group webinars addressing topics including returning to work, intimate relationships, nutrition, sleep hygiene, tobacco use, exercise, and leisure activities and testing or laboratory issues. Follow-up interviews were conducted during home visits, when available, or with the assistance of telephone, Skype, Viber or WhatsApp according to patient preference.

\section{Role of the designee}

Following informed consent, the designated family member or friend (hereafter called designee) continued through the study with the patient as a 'unit'. The designee attended the patient's educational sessions during stages 3 and 4 , with stage 2 being according to the family member preference. Recall that stage 2 deals with patient expectations, stage 3 with patient acceptance and problem-solving, and stage 4 with evaluations and internalising his/her locus of control. The designee and the patient attended the same sessions, and studied the same learning materials. Up to four family members were allowed to join in the educational sessions if requested. In stage 3, the designee was charged with learning and reinforcing educational material with the patient. In stage 4 , when instructed by study investigators, the designee would administer the KAP assessments to the patient. In addition to scores, the designee would provide additional information on the patient's home situation and current condition. Patients were assigned a code, and de-identified data were transmitted from the designee to investigators either by encrypted email, telephone, mail or in person.

\section{Rehabilitation plan}

All patients had similar inpatient rehabilitation programmes. For patients in the FCEM group, outpatients included daily exercise for $0-2 \mathrm{~h} /$ day. Exercise occurred between 8:00 and 10:00, and types included walking, jogging, bicycle, swimming, or other exercise according to patient preference or resource availability. Daily exercise was supervised by designated family members. Investigators randomly attended sessions in an unannounced fashion. Although not routinely involved, physical therapy consultation was available on investigator request. Exercise data were independently collected from the patient and their designated family member on a weekly basis ( $\kappa$ statistic $=0.9$ ). To measure the patients' walking distance, investigators provided them with a Fitbit (Fitbit, San Francisco, USA). Routine care included education on smoking cessation and education on food selection. Patients were provided printed materials, with dietician assessments available on request.

Patients in the control group received the same education and printed materials during their inpatient course. Patients exercised daily, at any time, for $\leq 2 \mathrm{~h}$ according to patient tolerance. Sessions were supervised by family members. Investigators did not attend sessions. Exercise data were independently collected from the patient and their designated family member on a weekly basis ( $\kappa$ statistic $=0.4$ ). Again, walking distance was measured using the Fitbit. Routine care included education on smoking cessation and education on food selection. Patients were provided printed materials, with dietician assessments available on request.

\section{Data collection}

Data collection tools consisted of six questionnaires including (1) demographic variables, (2) the FCEM, (3) the 36-Item Short Form Health Survey (SF-36), (4) the perceived stress, and (5) State and (6) Trait Anxiety questionnaires. In addition to questionnaires, results of serum creatinine, ejection fraction as measured on echocardiography, and cardiac catheterisation and stenting were also recorded.

\section{The FCEM questionnaire}

The FCEM questionnaire consisted of four dimensions: perceived threat, self-efficacy, self-esteem, and summative and formative evaluations. ${ }^{7}{ }^{32}$ Degree of patient empowerment was assessed via KAP questions. Each question was scored on a scale of 1-7 representing least to most empowerment, respectively. The maximum questionnaire score was 826 , and the lowest acceptable score was 620 (sensitivity $95 \%$, specificity 96\%).To determine the lowest acceptable postintervention score, analysis of the receiver operating characteristic (ROC) curve was performed and discussed in two qualitative expert panel rounds. Each expert panel consisted of 10 professional members (2 cardiologists, 1 intensivist, 1 nutritionist, 3 registered nurses, 1 psychologist, 1 psychiatrist and 1 physiatrist) and 22 patient/family member units. The $\kappa$ agreement correlation coefficient among the two qualitative expert panel rounds' results was 0.92 .

Validity of the FCEM questionnaires was assessed by face and content validities through both qualitative and quantitative means. Impact score of the questionnaire was calculated at 3.01; content validity ratio (CVR) with 10 panellists and Content Validity Index (CVI) were calculated at 0.78 and 0.85 , respectively. The reliability of the FCEM questionnaire was assessed by test-retest and Cronbach's $\alpha$ that was calculated at 0.89 and 0.92 , respectively. ${ }^{32}$

\section{SF-36 questionnaire}

The questionnaire consists of eight domains including physical functioning, physical role limitation, social functioning, bodily pain, mental health, mental role limitation, vitality and general health. Scoring of each domain 
was calculated independently and scores ranged from 0 (the worst) to 100 (the best). ${ }^{32} 33$ The SF-36 questionnaire is a validated tool ${ }^{33} 34$ whose reliability in this study was assessed by test-retest and Cronbach's $\alpha$ at 0.90 and 0.93 , respectively.

\section{The 14-item Perceived Stress Questionnaire (PSQ-14)}

Overall stress was measured using the validated PSQ-14. ${ }^{35}{ }^{36}$ PSQ-14 scores are obtained by reversing the scores on the seven positive items, including $0=4,1=3$, $2=2,3=1$ and $4=0$, then, summing across all 14 items. Scores range from 14 to $_{0 .} .^{37}$ The reliability of the PSQ-14 was assessed in this study by test-retest and Cronbach's $\alpha$ at 0.93 and 0.92 , respectively.

\section{The State and Trait Anxiety questionnaire}

Patient anxiety was assessed through the State-Trait Anxiety questionnaire. This validated tool has 20 items for assessing trait anxiety and state anxiety, respectively. ${ }^{38} 39$ All items are rated on a four-point scale ranging from very low (1 point) to very high (4 points). Higher scores indicate greater anxiety. ${ }^{38} 39$ The reliability of the State-Trait Anxiety questionnaire was assessed in this study by test-retest and Cronbach's $\alpha$ at 0.89 and 0.90 , respectively.

\section{Data analysis}

All analyses were performed using SPSS 22.0 (SPSS Inc, Chicago, IL). Frequency (per cent) and mean (SD) were presented for qualitative variables (gender, marital status, educational level, job and location of residence) and quantitative variables (age, body mass index and family size). Demographic variables were analysed using the $\chi^{2}$ test and independent Student's t test. The normality in variable distribution was analysed using the Kolmogorov-Smirnov test $(p>0$. 05). For the outcome measures of quality of life, perceived stress and state-and-trait anxiety, repeated measures analysis of variance (RANOVA) was performed followed by Sidak post hoc test.

The assumption of the sphericity of the covariance matrix was evaluated using Mauchly's test and, depending on the results of this test, $p$ values were presented on the basis of the Greenhouse-Geisser correction. In addition, Hotelling's $\mathrm{T}^{2}$ tests were used to evaluate the differences between the intervention and control groups at all time points, followed by independent samples Student's $\mathrm{t}$ tests for investigating the differences between the intervention and control groups separately. $p$ Values $<0.05$ were considered significant.

\section{RESULTS}

A total of 127 eligible patients were screened for the study. Fifty-one did not meet the inclusion criteria and six declined to participate. Seventy patient-family units were included and evenly randomised into two groups. Three patients died, including two in the control group and one in the intervention group. Seven patients were lost to follow-up, including five in the control group and two in the intervention group. Patient demographics were similar between groups (table 1).

\section{Clinical and physiological variables}

ST segment elevation MI was identified in 33 (94\%) patients in the intervention group and $31(89 \%)$ in the control group $(\mathrm{p}=0.77)$. Non-ST segment elevation MI was identified in $2(6 \%)$ versus $4(11 \%)$ patients $(\mathrm{p}=0.70)$. The incidence of cardiac catheterisation was similar between groups ( $55 \%$ vs $40 \%$; $\mathrm{p}=0.87$ ). Among those undergoing cardiac catheterisation, rates of stent placement did not differ significantly $(45 \%$ vs $60 \%$; $\mathrm{p}=0.62$ ). Although the baseline ejection fraction did not differ significantly between groups (table 2), the mean and median ejection fractions were significantly higher in the intervention group at measurements $2(\mathrm{p}=0.01)$ and $3(\mathrm{p}=0.001)$.

There were no events of repeat MI or emergent revascularisation in either group during the study period.

Renal function was similar between the intervention and control groups. Serum creatinine did not differ between groups at baseline $(1.48 \pm 0.34$ vs $1.39 \pm 0.40$; $\mathrm{p}=0.36)$, measurement $2(1.28 \pm 0.34$ vs $1.20 \pm 0.40 ; \mathrm{p}=0.41)$ and measurement $3(1.08 \pm 0.34$ vs $1.02 \pm 0.40 ; \mathrm{p}=0.55)$.

Pearson and Spearman correlation coefficients ( $r$ ) were used to compare exercise, weight loss and smoking cessation (data not presented). The correlation coefficients for exercise $(r=0.90)$, weight loss $(r=0.88)$ and smoking cessation $(\mathrm{r}=0.90)$ indicate that changes in these variables were similar between groups.

Exercise tolerance was further addressed by measuring the walking distance once a month. The mean walking distance was similar between groups at baseline but statistically improved in the FCEM group relative to controls (figure 2).

\section{Quality of life}

In this study, eight dimensions of quality of life were summarised in two comprehensive domains including physical dimensions (physical functioning, physical role limitation, bodily pain and general health) and mental dimensions (social functioning, mental health, mental role limitation and vitality). The results of the RANOVA model for physical and mental dimensions showed significant changes within and between groups over time $(\mathrm{p}<0.0001)($ table 3$)$.

Although the baseline physical health scores were similar between groups $(p=0.24)$, by the first postintervention assessments scores were significantly higher in the experimental group $(\mathrm{p}<0.0001)$ and remained so throughout the duration of the study (table 3). Similarly, the preintervention mental health scores were similar between groups $(p=0.48)$ but displayed a trend towards significant improvement in the experimental group by the first postintervention assessment and remained 
Table 1 Patient demographics

\begin{tabular}{|c|c|c|c|c|}
\hline Characteristics & $\begin{array}{l}\text { Total }(n=70) \\
\text { Mean } \pm S D\end{array}$ & $\begin{array}{l}\text { Intervention } \\
\text { group }(n=35)\end{array}$ & $\begin{array}{l}\text { Control group } \\
(n=35)\end{array}$ & $\begin{array}{l}\text { Statistical test } \\
\text { and } p \text { Value }\end{array}$ \\
\hline \multicolumn{5}{|l|}{ Age } \\
\hline Mean \pm SD & $61.40 \pm 12.83$ & $62.00 \pm 14.18$ & $60.80 \pm 11.51$ & $\begin{array}{l}t=0.389^{\star} \\
p=0.699\end{array}$ \\
\hline \multicolumn{5}{|l|}{ BMI } \\
\hline Mean \pm SD & $24.87 \pm 3.80$ & $24.70 \pm 3.5$ & $25.3 \pm 4.12$ & $\begin{array}{l}t=-0.364^{\star} \\
p=0.717\end{array}$ \\
\hline \multicolumn{5}{|l|}{ Family number } \\
\hline Mean $\pm S D$ & $5.37 \pm 1.91$ & $5.2 \pm 1.94$ & $5.54 \pm 1.91$ & $\begin{array}{l}t=-0.754^{*} \\
p=0.454\end{array}$ \\
\hline \multicolumn{5}{|l|}{ Gender, n (\%) } \\
\hline Male & $46(65.7 \%)$ & $22(62.9 \%)$ & $24(68.6 \%)$ & $\chi^{2}=2.470 \dagger$ \\
\hline Female & $24(34.3 \%)$ & 13 (37.1\%) & $11(31.4 \%)$ & $\begin{array}{l}d f=1 \\
p=0.116\end{array}$ \\
\hline \multicolumn{5}{|l|}{ Marital Status, n (\%) } \\
\hline Single & $1(1.4 \%)$ & $1(2.9 \%)$ & $0(0.00 \%)$ & - \\
\hline Married & $69(98.6 \%)$ & $34(97.1 \%)$ & $35(100.0 \%)$ & \\
\hline \multicolumn{5}{|l|}{ Living location, n (\%) } \\
\hline City & $36(51.4 \%)$ & $20(57.1 \%)$ & $16(45.7 \%)$ & $\chi^{2}=0.345 \dagger$ \\
\hline Countryside & $34(48.6 \%)$ & $15(42.9 \%)$ & $19(54.3 \%)$ & $\begin{array}{l}d f=1 \\
p=0.557\end{array}$ \\
\hline \multicolumn{5}{|l|}{ Job, n (\%) } \\
\hline Clerk & $12(17.1 \%)$ & $4(11.4 \%)$ & $8(22.9 \%)$ & $\chi^{2}=29.085 \dagger$ \\
\hline Labourer & $8(11.4 \%)$ & $4(11.4 \%)$ & $4(11.4 \%)$ & $\mathrm{df}=25$ \\
\hline Housekeeper & $23(32.9 \%)$ & $13(37.1 \%)$ & $10(28.6 \%)$ & $p=0.260$ \\
\hline Unemployed & $3(4.3 \%)$ & $1(2.9 \%)$ & $2(5.7 \%)$ & \\
\hline Retired & $11(15.7 \%)$ & $5(14.3 \%)$ & $6(17.1 \%)$ & \\
\hline Non-governmental & $13(18.6 \%)$ & $8(22.9 \%)$ & $5(14.3 \%)$ & \\
\hline \multicolumn{5}{|l|}{ Education level, n (\%) } \\
\hline Primary & $19(27.1 \%)$ & $8(22.9 \%)$ & $11(31.4 \%)$ & $\chi^{2}=8.809 \dagger$ \\
\hline Secondary & $30(42.9 \%)$ & $17(48.6 \%)$ & $13(37.1 \%)$ & $\mathrm{df}=4$ \\
\hline High/undergraduate & $21(30.0 \%)$ & $10(28.6 \%)$ & $11(31.4 \%)$ & $p=0.066$ \\
\hline
\end{tabular}

*Based on the independent Student's t test.

†Based on the $\chi^{2}$ test.

BMI, body mass index.

significant throughout the duration of the study $(\mathrm{p}<0.0001)$.

\section{Effect of the FCEM on perceived stress}

The results of the RANOVA model showed similar baseline values between the control and experimental groups $(p=0.48)$. A significant time trend was observed in the intervention group $(p<0.0001)$ with interaction between time and group $(\mathrm{p}<0.0001$; table 4$)$.

No significant time trend was noted in the control group ( $\mathrm{p}=0.143$ ). Of note, the difference within groups was achieved by the first follow-up assessment and

Table 2 Comparison of systolic ejection fraction between groups

\begin{tabular}{|c|c|c|c|c|c|c|c|c|c|}
\hline \multirow[b]{2}{*}{ Time } & \multicolumn{3}{|c|}{$\begin{array}{l}\text { Systolic ejection fraction } \\
(\mathrm{mm} \mathrm{Hg})\end{array}$} & \multicolumn{3}{|c|}{$\begin{array}{l}\text { Systolic ejection fraction } \\
(\mathrm{mm} \mathrm{Hg})\end{array}$} & \multirow[b]{2}{*}{$\begin{array}{l}\text { Within } \\
\text { FCEM } \\
\text { p Value }\end{array}$} & \multirow[b]{2}{*}{$\begin{array}{l}\text { Within } \\
\text { control } \\
\text { p Valuef }\end{array}$} & \multirow[b]{2}{*}{$\begin{array}{l}\text { Between } \\
\text { groups } \\
\text { p Value† }\end{array}$} \\
\hline & $\begin{array}{l}\text { FCEM } \\
(\mathrm{n}=35) \\
\text { Median } \\
(\mathrm{Q} 1-\mathrm{Q} 3)\end{array}$ & $\begin{array}{l}\text { Control } \\
(\mathrm{n}=35) \\
\text { Median } \\
(\mathrm{Q} 1-\mathrm{Q} 3)\end{array}$ & p Value* & $\begin{array}{l}\text { FCEM } \\
(n=35) \\
\text { Mean } \pm S D\end{array}$ & $\begin{array}{l}\text { Control } \\
(n=35) \\
\text { Mean } \pm S D\end{array}$ & p Value* & & & \\
\hline Preintervention & $44(33-50)$ & 37 (34-43) & 0.12 & $41.77 \pm 8.63$ & $38.86 \pm 6.73$ & 0.12 & 0.001 & 0.869 & 0.001 \\
\hline Measurement 2 & $46(34-52)$ & 38 (33-43) & 0.01 & $43.43 \pm 8.65$ & $38.66 \pm 6.79$ & 0.01 & & & \\
\hline Measurement 3 & $47(36-53)$ & $38(33-44)$ & 0.001 & $45.20 \pm 8.62$ & $38.89 \pm 6.58$ & 0.001 & & & \\
\hline
\end{tabular}




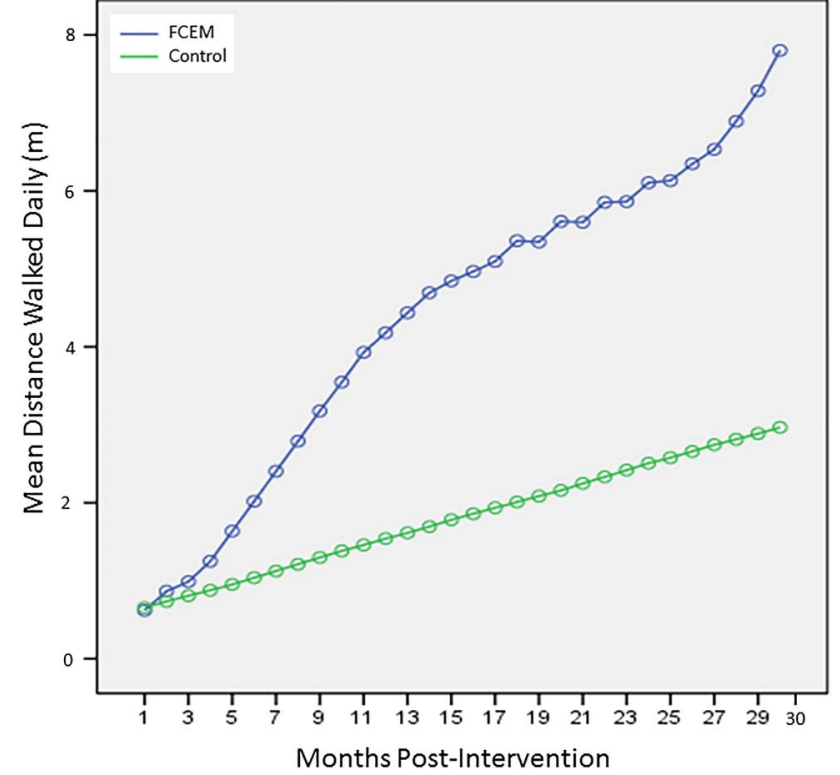

Figure 2 Distance walked daily. FCEM, Family-Centered Empowerment Model.

maintained throughout the duration of the study $(\mathrm{p}<0.0001)$.

\section{Effect of the FCEM on state and trait anxiety}

The results of the RANOVA model for state anxiety showed similar preintervention values between groups $(p=0.84)$ but significant improvement in state anxiety between groups by the first postintervention assessment $(\mathrm{p}<0.0001$; table 5$)$.

This trend persisted for the duration of the study. The time trend was significant in the intervention group and displayed interaction between time and group $(\mathrm{p}<0.0001)$, but no significant time trend was observed within the control $(\mathrm{p}=0.063)$ in the control group.

When assessing trait anxiety, the RANOVA model showed no significant time trend for either the intervention $(\mathrm{p}=0.089)$ or control $(\mathrm{p}=0.095)$ group, and interaction between time and group $(\mathrm{p}=0.075)$. Overall, no significant difference in trait anxiety was observed between groups (table 5).

\section{DISCUSSION}

CR is an outpatient model of chronic disease management for secondary CVD prevention and is a class I indication for patients with coronary heart disease. ${ }^{17}$ It can be defined as 'The coordinated sum of activities required to influence favorably the underlying cause of cardiovascular disease, as well as to provide the best possible physical, mental and social conditions, so that the patients may, by their own efforts, preserve or resume optimal functioning in their community and through improved health behavior, slow or reverse progression of disease'. ${ }^{40}$ In a meta-analysis, CR significantly reduced all-cause mortality by $13-26 \%$, cardiac mortality by 20 $36 \%$, myocardial re-infarction by $25-47 \%$, and risk factors. ${ }^{1}$ Additionally, it has been reported to have beneficial effects on quality of life, perceived stress and anxiety. ${ }^{18}{ }^{41}$ Patients who participate in CR tend to have a higher HRQoL and improved markers of mental health such as work resumption, and less stress and anxiety. It has been shown that about $80 \%$ of participants attending CR return to physical, mental and psychosocial functioning (including work) 1 year post-hospitalisation for MI. ${ }^{42}$ Although cost-effective in high-income countries, this has not been studied in LMICs. ${ }^{1} 20$ Despite recommendations, CR remains underutilised with low participation and adherence rates in both high income and LMICs. ${ }^{1}$ In the USA, fewer than $30 \%$ of eligible patients participate in these programmes, ${ }^{43}$ and fewer than $20 \%$ of eligible patients are referred to these programmes. ${ }^{44}$ Rates in Iran have not been well described. Many reasons for this underutilisation have been cited including age, female gender, geographic access, low socioeconomic status, organisational and patient factors, and patient education and understanding of the nature of CR and the associated benefits. ${ }^{19-21} 45$ Additionally, lower enrolment and higher dropout rates have been seen with patients with coexisting poor functional capacity and exercise habits, tobacco use and depression with an onset pre-CR. ${ }^{46}$

As a means to improve patient accessibility and compliance to CR programmes, both hybrid and homebased programmes were developed. Hybrid programmes incorporate both an ambulatory and home-based component. Participation in hybrid and home-based CR is associated with cost-effective and equivalent benefits to supervised programmes and offers support to maintain motivation, address anxiety and seek information. ${ }^{22-24}$ With advances in technology, hybrid home-based programmes have been developed that incorporate email, secure websites and video conferencing between patients and providers. Recently, the utility of smartphone applications to improve CR utilisation has also been investigated. $^{2147}$ It has been shown that hybrid CR may be a viable and effective tool in rural Iran. ${ }^{48}$

The FCEM is a model that we adapted to hybrid CR for the purpose of improving patient quality of life. It was initially designed to improve the care and outcomes of patients with chronic diseases and has previously been evaluated and validated in a number of chronic

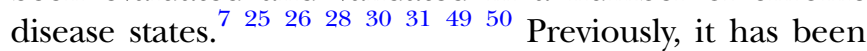
shown that the FCEM model may be feasible to use in the cardiac setting. ${ }^{72}$ Moreover, it has been reported to be effective among patients undergoing coronary artery bypass surgery. ${ }^{26}$ We investigated whether FCEM in the post-MI care and CR process is an effective means to decrease anxiety and perceived stress, and improve HRQoL in patients hospitalised for MI. This was the first study of its kind in this population. Control patients received standard $\mathrm{CR}$ while those in the intervention group received CR via the FCEM. For patients in the FCEM group, the designated key support relationships were identified and incorporated into their treatment 
Table 3 Quality of life dimensions including physical and mental health domains as determined by the SF-36 Questionnaire

\begin{tabular}{|c|c|c|c|c|c|c|c|}
\hline Domain & Measurement & $\begin{array}{l}\text { Intervention } \\
(\text { mean } \pm S D)\end{array}$ & $\begin{array}{l}\text { Control } \\
(\text { mean } \pm S D)\end{array}$ & p Value* & $\begin{array}{l}\text { p Value within } \\
\text { the FCEM } \\
\text { groupt }\end{array}$ & $\begin{array}{l}\text { p Value within } \\
\text { the control } \\
\text { group }{ }^{\dagger}\end{array}$ & $\begin{array}{l}p \text { Value } \\
\text { between } \\
\text { groups }^{\dagger}\end{array}$ \\
\hline \multirow[t]{11}{*}{ Physical health } & Baseline & $52.76 \pm 9.59$ & $50.11 \pm 9.58$ & 0.242 & $<0.0001$ & $<0.0001$ & $<0.0001$ \\
\hline & Measurement 2 & $82.05 \pm 6.40$ & $25.6 \pm 9.44$ & $<0.0001$ & & & \\
\hline & Measurement 3 & $82.04 \pm 9.30$ & $26.06 \pm 8.20$ & $<0.0001$ & & & \\
\hline & Follow-up 1 & $81.01 \pm 7.20$ & $24.24 \pm 10.24$ & $<0.0001$ & & & \\
\hline & Follow-up 2 & $86.13 \pm 4.51$ & $27.81 \pm 7.61$ & $<0.0001$ & & & \\
\hline & Follow-up 3 & $88.37 \pm 3.42$ & $20.10 \pm 4.65$ & $<0.0001$ & & & \\
\hline & Follow-up 4 & $88.54 \pm 3.35$ & $22.91 \pm 7.15$ & $<0.0001$ & & & \\
\hline & Follow-up 5 & $88.31 \pm 3.49$ & $22.25 \pm 7.69$ & $<0.0001$ & & & \\
\hline & Follow-up 6 & $87.66 \pm 3.47$ & $27.53 \pm 7.12$ & $<0.0001$ & & & \\
\hline & Follow-up 7 & $81.01 \pm 7.20$ & $34.24 \pm 10.24$ & $<0.0001$ & & & \\
\hline & Follow-up 8 & $85.21 \pm 4.65$ & $23.01 \pm 4.87$ & $<0.0001$ & & & \\
\hline \multirow[t]{11}{*}{ Mental health } & Baseline & $51.92 \pm 9.51$ & $53.64 \pm 10.87$ & 0.483 & $<0.0001$ & $<0.0001$ & $<0.0001$ \\
\hline & Measurement 2 & $80.11 \pm 7.40$ & $23.35 \pm 8.34$ & $<0.0001$ & & & \\
\hline & Measurement 3 & $81.21 \pm 7.30$ & $25.25 \pm 6.34$ & $<0.0001$ & & & \\
\hline & Follow-up 1 & $79.41 \pm 6.20$ & $24.15 \pm 7.14$ & $<0.0001$ & & & \\
\hline & Follow-up 2 & $85.72 \pm 3.23$ & $24.43 \pm 7.82$ & $<0.0001$ & & & \\
\hline & Follow-up 3 & $85.17 \pm 3.34$ & $18.33 \pm 4.45$ & $<0.0001$ & & & \\
\hline & Follow-up 4 & $84.69 \pm 3.45$ & $22.89 \pm 7.56$ & $<0.0001$ & & & \\
\hline & Follow-up 5 & $84.78 \pm 3.86$ & $24.52 \pm 8.15$ & $<0.0001$ & & & \\
\hline & Follow-up 6 & $84.04 \pm 3.78$ & $21.74 \pm 5.93$ & $<0.0001$ & & & \\
\hline & Follow-up 7 & $79.41 \pm 6.20$ & $24.15 \pm 7.14$ & $<0.0001$ & & & \\
\hline & Follow-up 8 & $83.86 \pm 3.81$ & $20.44 \pm 5.48$ & $<0.0001$ & & & \\
\hline
\end{tabular}

plan. Through stage 1, patients are encouraged to learn about themselves and their health so that they may be able to identify the ways in which they feel threatened by their illness. They then learn to assess their expectations of these situations (stage 2), and brainstorm in groups via the educational participation method to develop practical solutions (stage 3). Lastly, patients are taught to do a self-assessment and internalise their locus of control. In this way, patients are being taught techniques to cope with their chronic illness over the long haul.

In this study, we found improvements in physical health, mental health and quality of life in those patients receiving home CR using the FCEM as compared with those receiving standard home CR. The reasons for improvement are most likely multifactorial and may include patient encouragement, greater patient

Table 4 Perceived stress assessment

\begin{tabular}{|c|c|c|c|c|c|c|}
\hline Measurement & $\begin{array}{l}\text { Intervention } \\
\text { (mean } \pm S D)\end{array}$ & $\begin{array}{l}\text { Control } \\
\text { (mean } \pm S D)\end{array}$ & p Value* & $\begin{array}{l}\text { p Value within the } \\
\text { FCEM group }^{\dagger}\end{array}$ & $\begin{array}{l}\text { p Value within the } \\
\text { control group }^{\dagger}\end{array}$ & $\begin{array}{l}\text { p Value between } \\
\text { groups }^{\dagger}\end{array}$ \\
\hline Baseline & $34.57 \pm 3.83$ & $33.49 \pm 2.71$ & 0.483 & $<0.0001$ & 0.143 & $<0.0001$ \\
\hline Measurement 2 & $67.69 \pm 0.91$ & $32.69 \pm 3.11$ & $<0.0001$ & & & \\
\hline Measurement 3 & $70.26 \pm 0.54$ & $31.61 \pm 3.10$ & $<0.0001$ & & & \\
\hline Follow-up 1 & $68.17 \pm 1.51$ & $34.51 \pm 3.25$ & $<0.0001$ & & & \\
\hline Follow-up 2 & $68.46 \pm 0.95$ & $33.60 \pm 2.06$ & $<0.0001$ & & & \\
\hline Follow-up 3 & $68.34 \pm 1.14$ & $34.00 \pm 2.24$ & $<0.0001$ & & & \\
\hline Follow-up 4 & $68.54 \pm 1.07$ & $33.77 \pm 2.36$ & $<0.0001$ & & & \\
\hline Follow-up 5 & $68.34 \pm 1.06$ & $34.37 \pm 2.21$ & $<0.0001$ & & & \\
\hline Follow-up 6 & $68.40 \pm 1.19$ & $33.63 \pm 2.30$ & $<0.0001$ & & & \\
\hline Follow-up 7 & $68.60 \pm 1.38$ & $34.35 \pm 1.97$ & $<0.0001$ & & & \\
\hline Follow-up 8 & $64.71 \pm 1.98$ & $33.66 \pm 2.11$ & $<0.0001$ & & & \\
\hline
\end{tabular}


Table 5 State and trait anxiety assessment

\begin{tabular}{|c|c|c|c|c|c|c|c|}
\hline Anxiety type & Measurement & $\begin{array}{l}\text { Intervention } \\
\text { (mean } \pm S D)\end{array}$ & $\begin{array}{l}\text { Control } \\
\text { (mean } \pm S D)\end{array}$ & p Value* & $\begin{array}{l}\text { p Value within } \\
\text { the FCEM } \\
\text { group }^{\dagger}\end{array}$ & $\begin{array}{l}\text { p Value within } \\
\text { the control } \\
\text { group }^{\dagger}\end{array}$ & $\begin{array}{l}p \text { Value } \\
\text { between } \\
\text { groups }^{\dagger}\end{array}$ \\
\hline \multirow[t]{11}{*}{ State anxiety } & Baseline & $55.37 \pm 7.21$ & $55.06 \pm 6.23$ & 0.846 & $<0.0001$ & 0.143 & $<0.0001$ \\
\hline & Measurement 2 & $53.23 \pm 7.98$ & $73.14 \pm 6.05$ & $<0.0001$ & & & \\
\hline & Measurement 3 & $54.30 \pm 4.32$ & $76.09 \pm 4.54$ & $<0.0001$ & & & \\
\hline & Follow-up 1 & $55.83 \pm 6.69$ & $71.34 \pm 5.40$ & $<0.0001$ & & & \\
\hline & Follow-up 2 & $55.11 \pm 6.16$ & $74.34 \pm 3.51$ & $<0.0001$ & & & \\
\hline & Follow-up 3 & $54.69 \pm 6.43$ & $72.31 \pm 5.10$ & $<0.0001$ & & & \\
\hline & Follow-up 4 & $55.29 \pm 5.56$ & $71.97 \pm 4.94$ & $<0.0001$ & & & \\
\hline & Follow-up 5 & $55.00 \pm 6.34$ & $71.71 \pm 4.10$ & $<0.0001$ & & & \\
\hline & Follow-up 6 & $53.09 \pm 4.97$ & $72.00 \pm 5.04$ & $<0.0001$ & & & \\
\hline & Follow-up 7 & $51.94 \pm 3.12$ & $71.94 \pm 4.43$ & $<0.0001$ & & & \\
\hline & Follow-up 8 & $54.23 \pm 5.30$ & $72.26 \pm 4.24$ & $<0.0001$ & & & \\
\hline \multirow[t]{11}{*}{ Trait anxiety } & Baseline & $54.49 \pm 4.36$ & $53.43 \pm 3.85$ & 0.285 & 0.089 & 0.095 & 0.075 \\
\hline & Measurement 2 & $52.23 \pm 4.17$ & $53.40 \pm 4.56$ & 0.921 & & & \\
\hline & Measurement 3 & $51.23 \pm 4.80$ & $53.29 \pm 5.54$ & 0.729 & & & \\
\hline & Follow-up 1 & $53.86 \pm 3.87$ & $52.20 \pm 4.63$ & 0.109 & & & \\
\hline & Follow-up 2 & $53.43 \pm 3.85$ & $54.49 \pm 4.36$ & 0.406 & & & \\
\hline & Follow-up 3 & $52.20 \pm 4.63$ & $53.86 \pm 3.87$ & 0.801 & & & \\
\hline & Follow-up 4 & $54.06 \pm 3.69$ & $54.14 \pm 4.39$ & 0.930 & & & \\
\hline & Follow-up 5 & $52.20 \pm 4.63$ & $53.43 \pm 3.85$ & 0.231 & & & \\
\hline & Follow-up 6 & $54.49 \pm 4.36$ & $52.20 \pm 4.63$ & 0.099 & & & \\
\hline & Follow-up 7 & $53.20 \pm 4.63$ & $52.20 \pm 4.63$ & 0.942 & & & \\
\hline & Follow-up 8 & $55.06 \pm 3.69$ & $54.06 \pm 3.70$ & 0.843 & & & \\
\hline
\end{tabular}

understanding, positive reinforcement and the sense of accountability. This is reflected in the results of physical and mental health scores. Baseline scores were similar between groups; however, following deployment of the FCEM with its educational and support groups and use of remote follow-up (telephone, Skype, Viber or WhatsApp), there was a sharp discrepancy between groups favouring the FCEM-enhanced CR over standard home-based CR. Similar results were observed for perceived stress and state anxiety. The non-significance of the trait anxiety findings is important. State anxiety refers to a temporary condition in response to some perceived threat. Trait anxiety refers to the differences between people in terms of their tendency to experience state anxiety in response to the anticipation of a threat (ie, anxiety proneness). Thus, trait anxiety describes a personality characteristic rather than a temporary feeling. Although traits are enduring features which are part of one's personality, the expression of a trait can be changed over time, for example, with the use of long-term therapy. The importance of measuring trait anxiety in this study was to demonstrate that anxiety proneness, or the ability to generate state anxiety, was similar between groups. We observed stable levels of trait anxiety in both groups throughout the study. We believe that the attenuation in the rise in situational, or state, anxiety in the interventional group is a reflection of the patient's sense of empowerment in managing their health situation. Moreover, our interventions did not incorporate mandatory therapy or interventions that would change the trait anxiety of patients; thus, these levels remained stable.

Further study is needed to discern whether the FCEM is really improving patient health versus attenuating the decline that may occur following discharge for AMI. It may be that the FCEM method augments and maintains the education and empowerment that patients receive during their inpatient course. Additionally, the longterm sustainability of this method in this setting remains to be investigated.

\section{CONCLUSION}

The FCEM is an effective CR method for improving a patient's mental health and personal assessments of physical health following AMI.

\section{LIMITATIONS}

Physical health was measured by the validated SF-36 questionnaire. Data regarding specific modifiable risk factors (blood pressure, cholesterol, glycated haemoglobin) were not recorded.

Author affiliations

${ }^{1}$ Trauma Research Center and Nursing Faculty, Baqiyatallah University of Medical Sciences, Tehran, Iran 
${ }^{2}$ Department of Emergency Medicine, West Virginia University, Morgantown, West Virginia, USA

${ }^{3}$ Critical Care Medicine Department, Clinical Center, National Institutes of Health, Bethesda, Maryland, USA

${ }^{4}$ Department of Anesthesia and Critical Care Medicine, Loghman Clinical Research Development Center, Shahid Beheshti University of Medical Sciences, Tehran, Iran

${ }^{5}$ Department of Nursing Science, University of Eastern Finland, Kuopio, Finland

${ }^{6}$ Department of Nursing, Tarbiat Modares University, Tehran, Iran ${ }^{7}$ Department of Anesthesia, Shahid Modarres Hospital, Shahid Beheshti University of Medical Sciences, Tehran, Iran

${ }^{8}$ Anesthesia and Critical Care Medicine Department, Masih Daneshvari Hospital, Shahid Beheshti University of Medical Sciences, Tehran, Iran ${ }^{9}$ Anesthesia and Critical Care Medicine Department, Shohada Tajrish Hospital, Shahid Beheshti University of Medical Sciences, Tehran, Iran

${ }^{10}$ Anesthesia and Critical Care Medicine Department, Alborz University of Medical Sciences, Tehran, Iran

${ }^{11}$ Nephrology and Urology Research Center, Baqiyatallah University of Medical Sciences, Tehran, Iran

${ }^{12}$ Trauma Research Center, Baqiyatallah University of Medical Sciences,

Tehran, Iran

${ }^{13}$ Health Research Center, Baqiyatallah University of Medical Sciences, Tehran, Iran

Contributors Project Conception: AVA, FA. Project Design: AVA, ACM, MRHE, MK, FA. Data Acquisition: AVA, MRHE, FA, HAJM, MF, BF, SHA, SH, MG, SMMM, ZR, SJM, MI. Data Analysis: AVA, ACM, MK, FA. Manuscript Drafting: AVA, ACM, MRHE, MK, FA.

Funding This research was supported financially by internal funding from the Trauma Research Center of Baqiyatallah University of Medical Sciences, the Nursing Department of Tarbiat Modares University, and the Loghman Clinical Research Development Center, Shahid Beheshti University of Medical Sciences (\#340/5/5904)

Competing interests None declared.

Ethics approval Tarbiat Modares University (Tehran, Iran) and Baqiyatallah University of Medical Sciences (Tehran, Iran).

Provenance and peer review Not commissioned; externally peer reviewed.

Data sharing statement No additional data are available.

Open Access This is an Open Access article distributed in accordance with the Creative Commons Attribution Non Commercial (CC BY-NC 4.0) license, which permits others to distribute, remix, adapt, build upon this work noncommercially, and license their derivative works on different terms, provided the original work is properly cited and the use is non-commercial. See: http:// creativecommons.org/licenses/by-nc/4.0/

\section{REFERENCES}

1. Turk-Adawi KI, Grace SL. Narrative review comparing the benefits of and participation in cardiac rehabilitation in high-, middle- and low-income countries. Heart Lung Circ 2015;24:510-20.

2. Beaglehole R, Bonita R. Global public health: a scorecard. Lancet 2008;372:1988-96

3. Marrero SL, Bloom DE, Adashi EY. Noncommunicable diseases: a global health crisis in a new world order. JAMA 2012;307:2037-8.

4. Laslett LJ, Alagona P Jr, Clark BA III, et al. The worldwide environment of cardiovascular disease: prevalence, diagnosis, therapy, and policy issues: a report from the American College of Cardiology. J Am Coll Cardiol 2012;60(25 Suppl):S1-49.

5. Chen $\mathrm{CH}$, Chen YJ, Tu HP, et al. Benefits of exercise training and the correlation between aerobic capacity and functional outcomes and quality of life in elderly patients with coronary artery disease. Kaohsiung J Med Sci 2014;30:521-30.

6. Muhammad I, He HG, Koh K, et al. Health-related quality of life and its predictors among outpatients with coronary heart disease in Singapore. Appl Nurs Res 2014;27:175-80.

7. Vahedian Azimi A, Alhani F, Ahmadi F, et al. Effect of family-centered empowerment model on the life style of myocardial infarction patients. Iran J Crit Care Nurs 2010;2:1-2.
8. Cepeda-Valery B, Cheong AP, Lee A, et al. Measuring health related quality of life in coronary heart disease: the importance of feeling well. Int J Cardiol 2011;149:4-9.

9. Stafford L, Berk M, Reddy $\mathrm{P}$, et al. Comorbid depression and health-related quality of life in patients with coronary artery disease. J Psychosom Res 2007;62:401-10.

10. Stafford M, Soljak M, Pledge V, et al. Socio-economic differences in the health-related quality of life impact of cardiovascular conditions. Eur J Pub Health 2012;22:301-5.

11. Celano CM, Mastromauro CA, Lenihan EC, et al. Association of baseline anxiety with depression persistence at 6 months in patients with acute cardiac illness. Psychosom Med 2012;74:93-9.

12. Höfer S, Benzer W, Oldridge N. Change in health-related quality of life in patients with coronary artery disease predicts 4-year mortality. Int J Cardiol 2014;174:7-12.

13. Woodruffe S, Neubeck L, Clark RA, et al. Australian Cardiovascular Health and Rehabilitation Association (ACRA) core components of cardiovascular disease secondary prevention and cardiac rehabilitation 2014. Heart Lung Circ 2015;24:430-41.

14. Hawkes AL, Mortensen OS. Up to one third of individual cardiac patients have a decline in quality of life postintervention. Scand Cardiovasc J 2006;40:214-18.

15. Thombs BD, Ziegelstein RC, Stewart DE, et al. Physical health status assessed during hospitalization for acute coronary syndrome predicts mortality 12 months later. J Psychosom Res 2008;65:587-93.

16. Škodova Z, van Dijk JP, Nagyova I, et al. Psychosocial predictors of change in quality of life in patients after coronary interventions. Heart Lung 2011;40:331-9.

17. Smith SC Jr, Benjamin EJ, Bonow RO, et al. AHA/ACCF secondary prevention and risk reduction therapy for patients with coronary and other atherosclerotic vascular disease: 2011 update: a guideline from the American Heart Association and American College of Cardiology Foundation. Circulation 2011;124:2458-73.

18. Dalal HM, Zawada A, Jolly K, et al. Home based versus centre based cardiac rehabilitation: Cochrane systematic review and meta-analysis. BMJ 2010;340:b5631.

19. Turk-Adawi KI, Oldridge NB, Tarima SS, et al. Cardiac rehabilitation patient and organizational factors: what keeps patients in programs? J Am Heart Assoc 2013;2:e000418.

20. Turk-Adawi K, Sarrafzadegan N, Grace SL. Global availability of cardiac rehabilitation. Nat Rev Cardiol 2014;11:586-96.

21. Turk-Adawi K, Grace SL. Smartphone-based cardiac rehabilitation. Heart 2014;100:1737-8.

22. Korzeniowska-Kubacka I, Dobraszkiewicz-Wasilewska B, Bilinska M, et al. Two models of early cardiac rehabilitation in male patients after myocardial infarction with preserved left ventricular function: comparison of standard out-patient versus hybrid training programmes. Kardiol Pol 2011;69:220-6.

23. Korzeniowska-Kubacka I, Bilinska M, Dobraszkiewicz-Wasilewska B et al. Hybrid model of cardiac rehabilitation in men and women after myocardial infarction. Cardiol J 2015;22:212-18.

24. Szalewska D, Zielinski $\mathrm{P}$, Tomaszewski J, et al. Effects of outpatient followed by home-based telemonitored cardiac rehabilitation in patients with coronary artery disease. Kardiol Pol 2015;73:1101-7.

25. Alhani F. Evaluating of family centered empowerment model on preventing iron deficiency anemia [dissertation]. Tehran (Iran), Tarbiat Modares University, 2003.

26. Sanaie N, Nejati S, Zolfaghari M, et al. The effects of family-based empowerment on family cooperation in following patient treatment regime after coroner arteries bypass surgery. Modern Care $J$ 2014;11:19-27.

27. Sanaie $\mathrm{N}$, Nejati S, Zolfaghari $\mathrm{M}$, et al. The effect of family-centered empowerment in self efficacy and self esteem in patients undergoing coronary bypass graft surgery. J Res Dev Nurs Midwifery 2013;10:44-53

28. Seyed Nematollah Roshan F, Navipor H, Alhani F. The effect of education-based intervention using small group discussion in empowering adolescent girls to prevent iron deficiency anemia. J Patient Saf Qual Improv 2014;2:151-5.

29. Shojaeezadeh D, Tol A, Sharifirad G, et al. Effect of education program based on empowerment model in promoting self-care among type 2 diabetic patients in Isfahan. Razi J Med Sci 2013;20:18-31.

30. Heidari M, Alhani F, Kazemnejad A, et al. The effect of empowerment model on quality of life of Diabetic adolescents. Iran Ped 2007;17(1):87-94.

31. Changizi A, Zeighami R, Mirzaei E, et al. Family-oriented empowerment model influencing quality of life CABG patients. Journal of Nursing and Midwifery Sciences 2014;1:14-23. 
32. Vahedian-azimi A, Alhani F, Goharimogaddam K, et al. Effect of family-centered empowerment model on the quality of life in patients with myocardial infarction: A clinical trial study. Journal of Nursing Education 2015;4:8-22.

33. Montazeri A, Goshtasebi A, Vahdaninia M, et al. The Short Form Health Survey (SF-36): translation and validation study of the Iranian version. Qual Life Res 2005;14:875-82.

34. Rejeh N, Heravi-Karimooi M, Taheri Kharame Z, et al. Quality of life in patients with myocardial infarction and related factors: a cross sectional Study. Iran J Nurs Res 2015;9:1-11.

35. Cohen S, Kamarck T, Mermelstein R. A global measure of perceived stress. J Health Soc Behav 1983;24:385-96.

36. Vahedian Azimi A, Sadeghi M, Movafegh A, et al. The relationship between perceived stress and the top five heart disease characteristics in patients with myocardial infarction. ZUMS $J$ 2012;20:100-12.

37. Leung DY, Lam TH, Chan SS. Three versions of Perceived Stress Scale: validation in a sample of Chinese cardiac patients who smoke. BMC Public Health 2010;10:513.

38. Elliott TR, Shewchuk RM, Richards JS. Family caregiver social problem-solving abilities and adjustment during the initial year of the caregiving role. J Couns Psychol 2001;48:223.

39. Kvaal K, Ulstein I, Nordhus IH, et al. The Spielberger State-Trait Anxiety Inventory (STAI): the state scale in detecting mental disorders in geriatric patients. Int J Geriatr Psychiatry 2005;20:629-34.

40. Anderson LJ, Taylor RS. Cardiac rehabilitation for people with heart disease: an overview of Cochrane systematic reviews. Int J Cardiol 2014;177:348-61.

41. Coleman $\mathrm{K}$, Norris $\mathrm{S}$, Weston $\mathrm{A}$, et al. NHMRC additional levels of evidence and grades for recommendations for developers of guidelines. Canberra: NHMRC, 2005.

42. Boudrez H, De Backer $\mathrm{G}$. Recent findings on return to work after an acute myocardial infarction or coronary artery bypass grafting. Acta Cardiol 2000;55:341-9.
43. Thomas RJ, King M, Lui K, et al. AACVPR/ACC/AHA 2007 performance measures on cardiac rehabilitation for referral to and delivery of cardiac rehabilitation/secondary prevention services endorsed by the American College of Chest Physicians, American College of Sports Medicine, American Physical Therapy Association, Canadian Association of Cardiac Rehabilitation, European Association for Cardiovascular Prevention and Rehabilitation, Inter-American Heart Foundation, National Association of Clinical Nurse Specialists, Preventive Cardiovascular Nurses Association, and the Society of Thoracic Surgeons. J Am Coll Cardiol 2007;50:1400-33.

44. Boyden T, Rubenfire M, Franklin B. Will increasing referral to cardiac rehabilitation improve participation? Prev Cardiol 2010;13:192-201.

45. Nalini M. Outpatient cardiac rehabilitation use after coronary bypass surgery in the west of Iran. $J$ Cardiopulm Rehabil Prev 2014;34:263-70.

46. Harlan WR III, Sandler SA, Lee KL, et al. Importance of baseline functional and socioeconomic factors for participation in cardiac rehabilitation. Am J Cardiol 1995;76:36-9.

47. Varnfield M, Karunanithi M, Lee CK, et al. Smartphone-based home care model improved use of cardiac rehabilitation in postmyocardial infarction patients: results from a randomised controlled trial. Heart 2014;100:1770-9.

48. Najafi F, Nalini M. Hospital-based versus hybrid cardiac rehabilitation program in coronary bypass surgery patients in western Iran: effects on exercise capacity, risk factors, psychological factors, and quality of life. J Cardiopulm Rehabil Prev 2015;35:29-36.

49. Ghazavi Z, Minooei MS, Abdeyazdan Z, et al. Effect of family empowerment model on quality of life in children with chronic kidney diseases. Iran J Nurs Midwifery Res 2014;19:371

50. Teymouri F, Alhani F, Kazemnejad A. The effect of family-centered empowerment model on the Quality of life of school-age asthma children. J Nurs Res 2011;6:52-63. 